\title{
Economic evaluation of advanced practice physiotherapy models of care: a systematic review with meta-analyses
}

Simon Lafrance ${ }^{1,2^{*}}\left(\mathbb{D}\right.$, Anthony Demont ${ }^{3,4}$ (D) Kednapa Thavorn ${ }^{5,6}$ (D) Julio Fernandes ${ }^{7,8}$, Carlo Santaguida ${ }^{9}$ and François Desmeules ${ }^{1,2}$ (D)

\begin{abstract}
Background: The objective of this systematic review is to appraise evidence on the economic evaluations of advanced practice physiotherapy (APP) care compared to usual medical care.

Methods: Systematic searches were conducted up to September 2021 in selected electronic bibliographical databases. Economic evaluation studies on an APP model of care were included. Economic data such as health care costs, patient costs, productivity losses were extracted. Methodological quality of included studies was assessed with the Effective Public Health Practice Project tool and the Critical Appraisal Skills Programme checklist. Meta-analyses were performed and mean differences (MD) in costs per patient were calculated using random-effect inverse variance models. Certainty of the evidence was assessed with the GRADE Approach.

Results: Twelve studies ( $n=14,649$ participants) including four randomized controlled trials, seven analytical cohort studies and one economic modeling study were included. The clinical settings of APP models of care included primary, emergency and specialized secondary care such as orthopaedics, paediatrics and gynaecology. The majority of the included participants were adults with musculoskeletal disorders $(n=12,915)$. Based on low quality evidence, health system costs including salaries, diagnostic tests, medications, and follow-up visits were significantly lower with APP care than with usual medical care, at 2 to 12-month follow-up (MD: -139.08 €/patient; 95\%Cl: -265.93 to -12.23; $n=7648$ ). Based on low quality evidence, patient costs including travel and paid medication prescriptions, or treatments were significantly higher with APP care compared to usual medical care, at 2 to 6-month follow-up (MD: $29.24 € /$ patient; 95\%Cl: 0.53 to $57.95 n=1485$ ). Based on very low quality evidence, no significant differences in productivity losses per patient were reported between both types of care (MD: 590 $€ /$ patient; $95 \% \mathrm{Cl}$ : -100 to $1280 ; n=819$ ).

Conclusions: This is the first systematic review and meta-analysis on the economic evaluation of APP models of care. Low quality evidence suggests that APP care might result in lower health care costs, but higher patient costs compared to usual medical care. Costs differences may vary depending on various factors such as the cost methodology used and on the clinical setting. More evidence is needed to evaluate cost benefits of APP models of care.
\end{abstract}

Keywords: Physical therapy specialty, Physical therapists, Health planning, Economics, Cost analysis; health care costs, Health expenditures, "Physiotherapy", "Physical therapy" and "advanced practice"

\footnotetext{
* Correspondence: simon.lafrance.1@umontreal.ca

'School of Rehabilitation, Faculty of Medicine, Université de Montréal, Montreal, Quebec, Canada

${ }^{2}$ Maisonneuve-Rosemont Hospital Research Center, Université de Montréal

Affiliated Research Center, Montreal, Quebec, Canada

Full list of author information is available at the end of the article
}

(c) The Author(s). 2021, corrected publication 2021. Open Access This article is licensed under a Creative Commons Attribution 4.0 International License, which permits use, sharing, adaptation, distribution and reproduction in any medium or format, as long as you give appropriate credit to the original author(s) and the source, provide a link to the Creative Commons licence, and indicate if changes were made. The images or other third party material in this article are included in the article's Creative Commons licence, unless indicated otherwise in a credit line to the material. If material is not included in the article's Creative Commons licence and your intended use is not permitted by statutory regulation or exceeds the permitted use, you will need to obtain permission directly from the copyright holder. To view a copy of this licence, visit http://creativecommons.org/ licenses/by/4.0/. The Creative Commons Public Domain Dedication waiver (http://creativecommons.org/publicdomain/zero/1. 0/) applies to the data made available in this article, unless otherwise stated in a credit line to the data. 


\section{Background}

Health care expenditures have been drastically increasing over several decades. In the last 50 years, the proportion of the gross domestic product dedicated to health care has almost doubled among Organisation for Economic Co-operation and Development (OECD) countries [1]. Physical disorders, leading to pain and disability represent an important proportion of health care costs, with annual expenditure up to USD 635 billion for the treatment of pain in the United States [2-4]. Despite this increase in health care spending, timely access to care remains problematic $[5,6]$. Physicians have increasing difficulty meeting this growing demand and simply increasing the number of physicians does not appear to be an efficient solution, especially in the long term [5-7]. Health care delivery transformations are warranted in order to offer more efficient care to a growing number of patients $[8,9]$. Expanding and extending clinical roles of allied health care providers appears to be a promising solution to manage this growing demand $[10,11]$.

For acute and chronic physical disorders, the use of advanced practice physiotherapy (APP) models of care (MoC) has been proposed as a potential solution to improve health care access [12-17]. The ultimate goals of these $\mathrm{MoC}$ are to provide best practice care while improving health care access in a cost-effective manner. APP MoC may include role enhancements and role substitution for physiotherapists related to traditionally performed medical or controlled acts, such as diagnosis, ordering imaging or laboratory tests, triaging potential surgical candidates and referring of patients to other medical specialists $[13,18]$. APP MoC can be developed and implemented in various clinical settings such as in primary, emergency and secondary care. In these models, more complex cases requiring medical assessment or potential surgical candidates are referred to medical doctors while less complex patients can be managed independently by advanced practice physiotherapists (APPs).

Previous systematic reviews report that APP MoC improves access to care by reducing waiting time for an initial consultation while providing at least comparable quality of care and retaining high patient satisfaction for adults with musculoskeletal disorders (MSKDs) [12-15, 17, 19]. Three systematic reviews, evaluating several outcomes and not only economic evaluations of APP MoC have been published. The first review was published nearly a decade ago [13]. One review was limited to studies in emergency departments [14], and the other one included studies in primary and secondary care [19]. Based on two trials in emergency care, Matifat et al. [14] reported no significant differences in terms of health care costs between APP care and usual medical care (UMC) and Marks et al. [19] reported that APP care may be cost saving based on one trial in orthopaedic care. None of these performed a recent comprehensive review of all studies on the economic evaluation of APP $\mathrm{MoC}$ and neither performed a meta-analysis. Therefore, the aim of this systematic review is to summarize and appraise the available evidence on the economic evaluations of APP MoC in primary, emergency, and secondary care in terms of health care system costs, patient costs and productivity losses.

\section{Methods}

This review protocol is available online on Prospero (https://www.crd.york.ac.uk/prospero/). The registration number is: CRD42020185050. There were no amendments to the protocol.

\section{Literature search}

Bibliographical searches were conducted using four electronic databases (Medline, Embase, Cochrane Central and CINAHL) from their inception to September 2021, using terms related to advanced practice, physiotherapy and economic evaluation (full search strategy in supplementary materials). The reference lists of identified published studies and of previous relevant systematic reviews were screened for any additional eligible studies.

\section{Study selection}

Two reviewers (SL and $\mathrm{AD}$ ) independently reviewed titles and abstracts to identify relevant studies. Consensus of the two reviewers was needed to include the studies. A third reviewer (FD) was available if consensus was not achieved by the two initial reviewers. Articles were included if they met the following inclusion criteria: 1- included the evaluation of an APP MoC; APP was defined as a role involving a higher level of practice and responsibilities for physiotherapists including more complex clinical responsibilities, role enhancement and medical role substitution with or without the addition of delegated medical or controlled acts [18]; 2- presented any type of economic evaluation including costminimization, cost-effectiveness, cost-utility or cost-benefit analyses and from any economic perspective (health care system, patient or societal); 3- enrolled patients were cared by an APP, and 4- articles were written in French or English. Studies including patients with cancer-related pain, degenerative neurological disorder and/or autoimmune disorders were excluded.

\section{Data extraction}

Data of included studies were extracted with a predefined standardized form that documented study design, population, study setting, number of participants, patients diagnoses and characteristics, types of APP MoC and UMC, the costs measured (health care system costs, patient costs and productivity losses), types of economic evaluations (cost-minimization, cost-effectiveness, costutility or cost-benefit analyses) and length of the follow- 
up. Cost-minimization represents an analysis of the difference in costs between APP care and UMC when the clinical effectiveness of the two approaches is considered equivalent. Data extraction was performed by one evaluator (SL) and verified by a second evaluator (AD). When data were missing or incomplete, original authors were contacted to obtain complete data and results.

\section{Methodological quality assessment}

The methodological quality of included studies was assessed with the Effective Public Health Practice Project (EPHPP) tool (available at http://www.ephpp.ca/tools.html). The EPHPP tool is a generic appraisal tool developed for use in public health research. The tool can evaluate any study design and it appraises selection bias, study design, confounding, blinding, data collection method and number of withdrawals/dropouts. The EPHPP tool has appropriate content and construct validity [20] as well as good intra- and inter-rater reliability $[20,21]$. Since the EPHPP tool is not specific to economic studies, sections A and B of the Critical Appraisal Skills Programme (CASP) checklist developed by the Public Health Resource Unit, was also used in order to assess specifically the quality of the economic analyses [22]. The CASP checklist only evaluates the methodological quality of the economic component of a study and does not evaluate other methodological biases such as selection bias and study design, confounding, blinding or number of withdrawals/dropouts. The assessment of the methodological quality using these two complementary tools was performed by two independent evaluators (SL and $\mathrm{AD}$ ); final scores were obtained through a consensus. In case of disagreement, a third reviewer was available to facilitate consensus (FD). Sources of funding were also verified.

\section{Data synthesis}

All costs were adjusted for inflation according to the study's original country and then converted to euro for the 2020 fiscal year based on the Bank of England's inflation and conversion rates, since the majority of the original studies calculated costs to euro [23]. Rates used for conversion and inflation adjustment are available in supplementary material.

Randomized controlled trials (RCTs) and cohort studies that measured costs from similar perspectives, such as the costs from the health care system, patients' costs or productivity losses were pooled together into separate meta-analyses through Review Manager (RevMan 5.4, The Cochrane Collaboration, Copenhagen, Denmark). Meta-analyses were also calculated according to the clinical settings (primary, emergency, orthopaedic or paediatric orthopaedic care). Two secondary meta-analyses were conducted: one including only RCTs and one including studies comparing APP MoC to nurse practitioners care (and not compared to UMC). Mean differences (MD) in costs were calculated. The inverse variance method was used to weigh each study and was calculated using random effect models, as it "provide a result that may be viewed as an average intervention effect" [24]. Missing standard deviations were calculated using the RevMan Calculator (available at https://training.cochrane.org/ resource/revman-calculator). Alpha level was set at 0.05 . For studies not pooled into meta-analyses, a narrative synthesis was performed.

The GRADE Approach (Grading of Recommendations, Assessment, Development and Evaluations) was used to grade the overall quality of the evidence. For results based only on RCTs certainty was initially considered as high while pooled results from RCTs and observational studies combined were considered as moderate. Thereafter, certainty could be rated down based on factors such as risk of bias, imprecision, inconsistency, indirectness and potential publication bias while it could be rated up if a large magnitude of effect was observed $[25,26]$.

\section{Results}

From the 18 potentially relevant articles identified through titles and abstract review, 12 studies $(n=14,649$ participants; 14 articles) met the eligibility criteria after full-text review (Fig. 1). Detailed characteristics of included studies are presented in Table 1. Studies were excluded because they include no patient cared by an APP [27], did not study an APP MoC [28, 29] or did not include economic data [30].

\section{Study design and types of economic evaluations}

Four RCTs [31-34], three prospective cohort studies [35-37], four retrospective cohort studies [38-42] and one economic modeling study ( 2 articles) $[43,44]$ were included.

All included studies measured health care system costs, five studies measured patient costs [32-35, 37] and two studies measured patients' productivity losses [31, 34]. Four observational studies only included health care practitioner's salary in their health care system costs outcomes (Table 3).

Cost-minimization analyses were performed in all included studies except one modeling study. A cost-utility analysis and a cost-benefit analysis were performed in one RCT [31]. One modeling study used a Markov model analysis in one manuscript [43] and a discrete event simulation with dynamic queuing [44] in another paper to assess the cost-utility of APP MoC.

APP care was compared to care provided by orthopaedic surgeons [32, 35, 36, 38, 43, 44], emergency physicians [33, 34] family physicians [31, 37, 40,41] or gynecologists [39] . Two studies also compared APP care to nurse practitioners care [33, 40, 41] while one study also compared APP care to osteopathic physicians and 


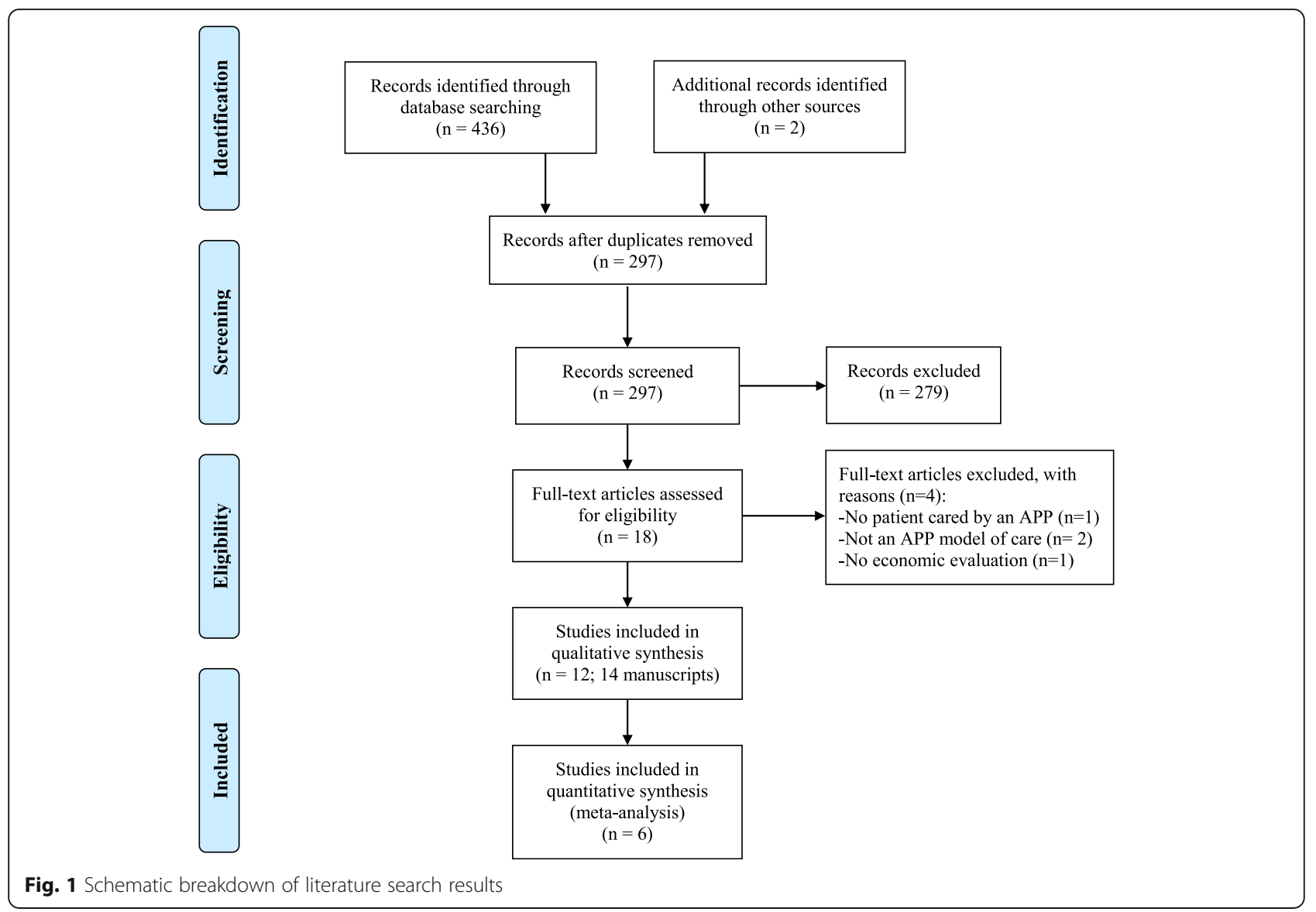

physician assistant care [40, 41]. One study compared APP telehealth care to APP face-to-face care [42].

\section{Clinical settings and participants}

Three studies were performed in primary care clinics $[31,37,40,41]$, two in emergency departments [33, 34] and seven in specialized care including four in adults orthopaedic outpatient clinics [32, 35, 42-44], two in paediatrics orthopaedic outpatient clinics $[36,38]$ and one in a gynaecology and urology outpatient clinic [39]. All included studies were conducted in Western Countries. More specifically, four studies were conducted in the United Kingdom [32-34, 38], four in Australia [35, 39, 42-44], two in Sweden [31, 37], one in Ireland [31, $36]$ and one in the United States [40, 41].

A total of 14,649 participants were included and participants were adults with MSKDs $(n=12,915)$ or pelvic floor disorders $(n=268)$ or infant or children with MSKDs $(n=1466)$. Female gender accounted for $53 \%$ of the included participants $(n=2334 / 4432)$. Participants in the included studies were new patients referred for an initial APP consultation in all studies except in the study by Harding et al. [35] which included follow-up of hip or knee arthroplasty patients. Overall, there was no significant difference in baseline pain, disability, and quality of life among participants assigned to APP care or UMC in RCTs as described in Table S2 in supplementary materials.

Types of advanced practice physiotherapy models of care In all included studies, APPs autonomously assessed, managed and referred patients to medical specialists when relevant, except in the RCTs by Bornhöft et al. [31] and by McClellan et al. [33] in which it is unclear whether APPs were able to make direct referrals to medical specialists. APPs could prescribe diagnostic imaging tests such as plain radiographs or MRI in nine studies [32, 34-37, 40-44], blood tests in three studies [32, 35, 36], nerve conduction studies in one study [32], urodynamic investigation in one study [39] and certain medications such as nonsteroidal anti-inflammatory drugs in one study $[40,41]$. APPs could refer patients for corticosteroid injections in one study $[43,44]$. None of the APP $\mathrm{MoC}$ systematically provided a comprehensive rehabilitation intervention to participants and most MoC did not specify the detail of the conservative care offered [31, 33, 34, 38, 40, 41, 43, 44]. In four MoC, APPs could refer patients to outpatient physiotherapy [35, 36, 39] or provide education and prescribe a self-management 


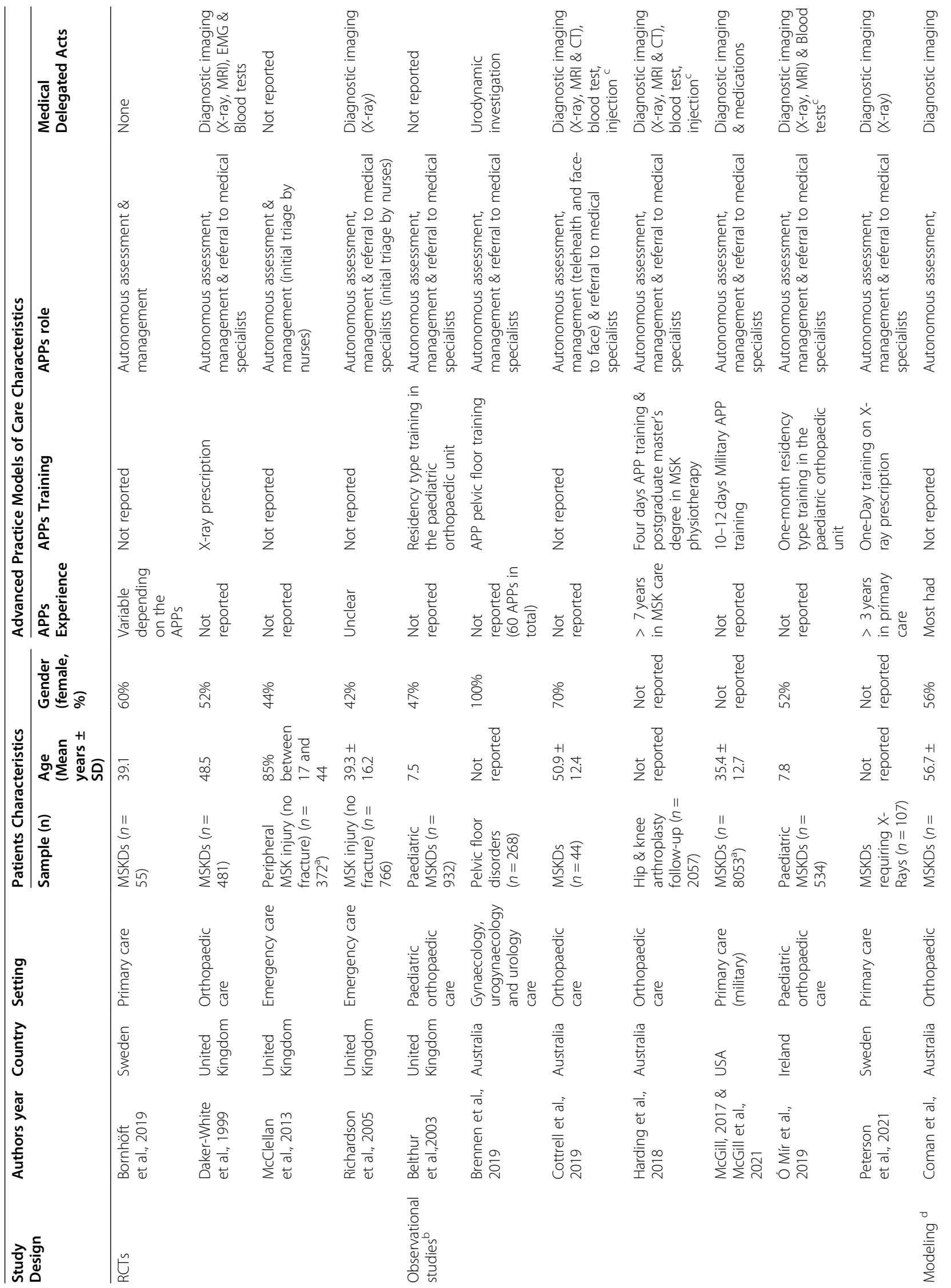




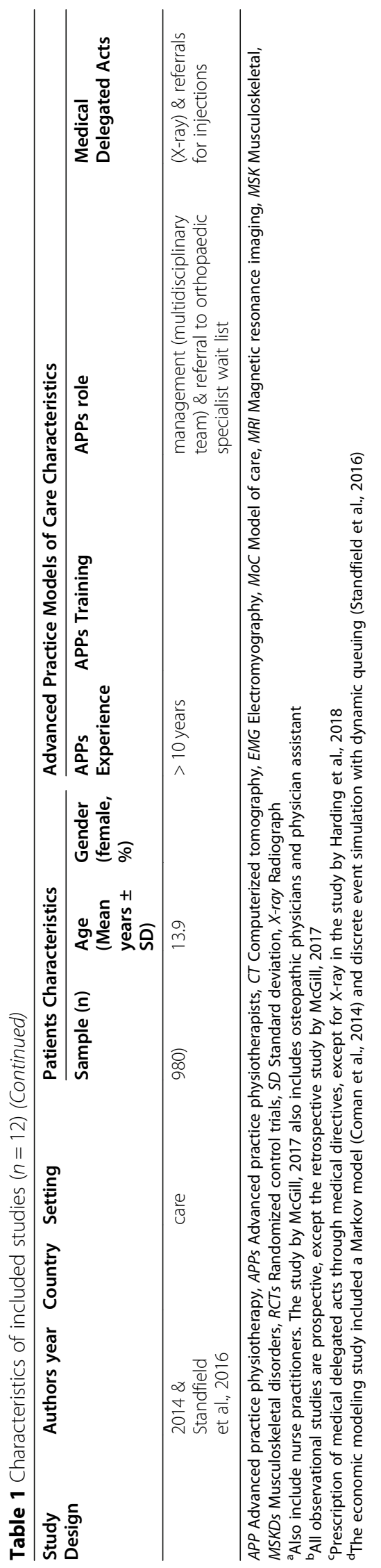


exercise program to patients in one study [32]. Full details are presented in Table 1.

\section{Quality of the included studies}

Based on the EPHPP tool, one study was considered of high quality [31], six of moderate quality [32-35, 37, 40, 41] and five of low quality [36, 38, 39, 42-44]. Presence of confounders was unclear in all observational studies, except for the study by Belthur et al. [38] in which a confusion bias was present as patients with more severe conditions and more likely to require complex care were only seen by medical doctors. Blinding of the outcome assessors and/or participants was unclear in all observational studies and in one RCT [34]; outcome assessors, but not participants were blinded in two RCTs $[31,33]$ and both outcomes assessors and participants were not blinded in one RCT [32].

Based on the CASP checklist, the effects of the interventions were measured appropriately only in the four RCTs and in the modeling study [31-34, 43, 44]. Costs were properly measured and included all important resources in four studies [31, 32, 40, 41, 43, 44]. Incremental analyses were performed in two studies [31, 43, 44].
Sensitivity analyses were performed in four studies [33, 42-44]. Details are presented in Table 2.

\section{Economic evaluation of advanced practice physiotherapy care compared to usual medical care Cost-minimization analyses}

Four RCTs and six observational studies performed costminimization analyses. The four RCTs reported that the two $\mathrm{MoC}$ were equivalent in terms of clinical effectiveness while the six observational studies considered the two MoC as equivalent but only based on previous published studies.

For health system costs, six studies (four RCTs and two cohorts) in primary, emergency, and specialized secondary care (orthopaedic and paediatric) were pooled into a meta-analysis. One of the included studies was of high quality [31], four of moderate [32-34, 40, 41] and one of low quality [36]. Health care system costs per patient were significantly lower with APP care than with UMC (MD: $139.08 € ; 95 \%$ CI: -265.93 to $-12.23 ; n=7648 ; \mathrm{I}^{2}=99 \%$; $p=0.03$ ) at 2 to 12 -month follow-up, as presented in Fig. 2. Among the different clinical settings, health care system costs with APP care were significantly lower in

Table 2 Methodological Quality of included studies based on the Effective Public Health Practice Project Tool and on the Critical Appraisal Skills Programme (CASP) checklist for economic the economic analyses component $(n=12)$

\begin{tabular}{|c|c|c|c|c|c|c|c|c|c|c|c|c|c|c|c|c|}
\hline & \multirow[b]{2}{*}{ Author, year } & \multicolumn{7}{|c|}{ Effective Publich Health Practice Project (EPHPP) tool for methodological quality } & \multicolumn{8}{|c|}{ Critical Appraisal Skills Programme (CASP) checklist for economic outcomes } \\
\hline & & $\begin{array}{l}\text { Selection } \\
\text { bias }\end{array}$ & Study design & Confounders & Blinding & $\begin{array}{l}\text { Data } \\
\text { collection }\end{array}$ & $\begin{array}{l}\text { Withdrawals } \\
\text { \& dropouts }\end{array}$ & Global rating & $\begin{array}{l}\text { 1. Defined } \\
\text { question }\end{array}$ & \begin{tabular}{|c|}
2. \\
Competing \\
alternatives \\
\end{tabular} & $\begin{array}{l}\text { 3. Program } \\
\text { effective }\end{array}$ & $\begin{array}{l}\text { 4. Effect } \\
\text { measures }\end{array}$ & $\begin{array}{l}\text { 5. Cost } \\
\text { measures }\end{array}$ & $\begin{array}{c}\text { 6. Cost } \\
\text { adjusted for } \\
\text { time }\end{array}$ & \begin{tabular}{|c|}
8. \\
Incremental \\
analysis
\end{tabular} & $\begin{array}{c}\text { 9. Sensitivity } \\
\text { analysis }\end{array}$ \\
\hline \multirow{4}{*}{$\underset{\mathscr{c}}{\tilde{L}}$} & Bornhöft et al., 2019 & & + & & $?$ & & $?$ & & & & & & & & & \\
\hline & $\begin{array}{c}\text { Daker-White et al., } \\
1999\end{array}$ & ? & & ? & & & ? & ? & & & & & & & & \\
\hline & McClellan et al., 2013 & ? & & & ? & & $?$ & $?$ & & & & & & & & \\
\hline & Richardson et al., 2005 & & & & $?$ & & & $?$ & & & & & ? & & & ? \\
\hline \multirow{7}{*}{ 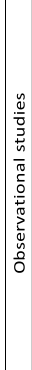 } & Belthur et al.,2003 & & ? & & ? & & & & & & & & & & & \\
\hline & Brennen et al., 2019 & + & ? & & ? & & ? & & & & & & & & & \\
\hline & Cottrell et al., 2019 & ? & $?$ & & $?$ & $?$ & $?$ & & & & & & & & & \\
\hline & Harding et al., 2018 & + & ? & & ? & ? & & ? & & & & & & & & \\
\hline & $\begin{array}{c}\text { McGill, } 2017 \text { \& McGill } \\
\text { et al., } 2021\end{array}$ & + & $?$ & & $?$ & + & ? & ? & & & & & & & & \\
\hline & Ó Mír et al., 2019 & ? & ? & & ? & ? & & & & & & & & & & \\
\hline & Petersen et al., 2021 & $?$ & $?$ & & ? & $?$ & + & $?$ & & & & & & & & \\
\hline$\frac{\overline{\mathrm{z}}}{\mathrm{o}}$ & $\begin{array}{l}\text { Coman et al., } 2014 \text { \& } \\
\text { Standfield et al., } 2016\end{array}$ & ? & & & ? & & ? & & & & & & & & & \\
\hline
\end{tabular}

EPHPP: Green = Strong; Yellow = Moderate; Red = Weak

CASP: Green = Yes; Yellow = Unclear; Red = No

RCTs Randomized controlled trials

Model: Economic Modeling analyses

t: A "no" was provided when clinical effectiveness was not directly assessed in the study but demonstrated in previous studies

\#: Costs were not adjusted in most studies, but follow-up periods were short (less than 12 months, except in McGill, 2017)

CASP checklist: 1 . Was a well-defined question posed? 2. Was a comprehensive description of the competing alternatives given? 3. Does the paper provide evidence that the program would be effective? (i.e., would the program do more good than harm?) 4 . Were the effects of the intervention identified, measured and valued appropriately? 5. Were all important and relevant resources required, and health outcome costs for each alternative identified, measured in appropriate units and valued credibly? 6. Were costs and consequences adjusted for different times at which they occurred (discounting)? 7 . What were the results of the evaluation? (See result section) 8. Was an incremental analysis of the consequences and cost of alternatives performed? 9 . Was an adequate sensitivity analysis performed? 
orthopaedic care and paediatric orthopaedic care but significantly higher in emergency care. A secondary analysis of health system costs per patient including only RCTs reported no significant difference between the costs of APP care and UMC (MD: $-52.84 €$ in favor of APP; 95\%CI: -153.35 to $47.66 ; \mathrm{I}^{2}=87 \% ; n=1540 ; p=0.30$ ) (Fig. S1 in supplementary material). Four observational studies could not be pooled since standard deviations were not available in the original publications or after contacting the authors [35, 37-39]. Mean health system costs were lower with APP care than with UMC in these four studies. When excluding the two trials in emergency care, all included studies reported a lower mean health care system costs per patient with APP care than with UMC (range MD: -12.19 to $-524.92 € ; 8$ studies), as presented in Table 3.

For patient costs, two moderate quality RCTs in emergency $[33,34]$ and one moderate quality RCT in orthopaedic care [32] were pooled into a meta-analysis. Patient costs per patient were significantly higher with APP care than UMC (MD: $29.24 €$; $95 \%$ CI: 0.53 to $57.95 ; n=1485 ; \mathrm{I}^{2}=0 \%$; $p=0.05)$ at 2 to 6-month follow-up, as showed in Fig. 3.

For productivity losses, one high quality RCT in primary care [31] and one moderate quality RCT in emergency care [34] were pooled into a meta-analysis. No significant differences between APP MoC and UMC were reported (MD: $590 € /$ patient in favour of UMC; $95 \%$ CI: -100 to $\left.1280 ; n=819 ; \mathrm{I}^{2}=0 \% ; p=0.1\right)$ at 6 to 12 month follow-up, as presented in Fig. 4.

\section{Cost-utility and cost-benefit analyses}

The high quality RCT by Bornhöft et al. [31] performed a cost-utility analysis comparing APP care and UMC. The incremental cost-effectiveness ratio (ICER) mean estimation was that APP care was more effective and cost saving than $\mathrm{UMC}$, and that there was only a 7 to $8 \%$ chance that UMC was more effective and cost saving. Based on the costbenefit analysis, there was $85 \%$ chance that APP care was cost-effective at a willingness to pay of 20,000 €/QALY.

Based on the modeling study by Coman et al. [43], an APP MoC involving an APP-led multidisciplinary team management (APP, occupational therapist, psychologist, pharmacist, etc.) for non-surgical candidates was more expensive than UMC in orthopaedic care by $72.32 € /$ patient but resulted in a net incremental benefit of 0.23 QALY. Regarding the cost-utility analysis, the mean incremental cost-effectiveness ratio (ICER) was $319.62 € / \mathrm{QALY}$, with a credibility interval with a range from a dominant scenario where the multidisciplinary APP MoC was more effective and cost-saving in $37 \%$ of cases to $2237.98 € /$ QALY for the $95 \%$ upper limit of the credibility interval. Based on

\begin{tabular}{|c|c|c|c|c|c|c|c|c|c|c|}
\hline \multirow{3}{*}{$\begin{array}{l}\text { Study or Subgroup } \\
\text { 1.4.1 Primary care }\end{array}$} & \multicolumn{2}{|c|}{ APP care } & \multicolumn{4}{|c|}{ UMC } & & \multirow{3}{*}{$\begin{array}{l}\text { Mean Difference } \\
\quad \text { IV, Random, } 95 \% \mathrm{Cl}\end{array}$} & \multirow{2}{*}{\multicolumn{2}{|c|}{$\begin{array}{l}\text { Mean Difference } \\
\text { IV, Random, } 95 \% \mathrm{CI}\end{array}$}} \\
\hline & \multirow{2}{*}{ Mean } & \multirow{2}{*}{ SD } & \multirow{2}{*}{ Total } & \multirow{2}{*}{ Mean } & \multirow[t]{2}{*}{ SD } & \multirow[t]{2}{*}{ Total } & & & & \\
\hline & & & & & & & Weight & & \multirow[b]{3}{*}{-} & \\
\hline Bornhoft 2019 RCT & 245.4647 & 359.4825 & 28 & 261.639 & 356.2923 & 27 & $13.3 \%$ & $-16.17[-205.36,173.01]$ & & \\
\hline $\begin{array}{l}\text { McGill } 2017 \text { Obs } \\
\text { Subtotal }(95 \% \text { CI) }\end{array}$ & 0 & 789.74 & $\begin{array}{l}1781 \\
1809\end{array}$ & 428.08 & 789.74 & $\begin{array}{l}3582 \\
3609\end{array}$ & $\begin{array}{l}18.5 \% \\
31.8 \%\end{array}$ & $\begin{array}{l}-428.08[-472.96,-383.20] \\
-232.80[-635.92,170.32]\end{array}$ & & \\
\hline \multicolumn{9}{|c|}{$\begin{array}{l}\text { Heterogeneity: } \text { Tau }^{2}=79912.54 ; \mathrm{Chi}^{2}=17.24, \mathrm{df}=1(\mathrm{P}<0.0001) ;\left.\right|^{2}=94 \% \\
\text { Test for overall effect: } Z=1.13(P=0.26)\end{array}$} & & \\
\hline \multicolumn{11}{|l|}{ 1.4.2 Emergency care } \\
\hline McClellan 2013 RCT & 108.78 & 183.7 & 126 & 87.41 & 156.45 & 123 & $18.6 \%$ & $21.37[-20.98,63.72]$ & & $f-$ \\
\hline $\begin{array}{l}\text { Richardson } 2005 \mathrm{RCT} \\
\text { Subtotal }(95 \% \mathrm{Cl})\end{array}$ & 283.56 & 276.07 & $\begin{array}{l}382 \\
508\end{array}$ & 251.75 & 185.33 & $\begin{array}{l}384 \\
507\end{array}$ & $\begin{array}{l}18.7 \% \\
37.3 \%\end{array}$ & $\begin{array}{l}31.81[-1.51,65.13] \\
27.82[1.63,54.00]\end{array}$ & & 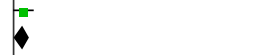 \\
\hline \multicolumn{11}{|c|}{$\begin{array}{l}\text { Heterogeneity: } \mathrm{Tau}^{2}=0.00 ; \mathrm{Chi}^{2}=0.14, \mathrm{df}=1(\mathrm{P}=0.70) ; \mathrm{I}^{2}=0 \% \\
\text { Test for overall effect: } Z=2.08(P=0.04)\end{array}$} \\
\hline \multicolumn{11}{|l|}{ 1.4.3 Orthopaedic care } \\
\hline $\begin{array}{l}\text { Daker-W } 1999 \mathrm{RCT} \\
\text { Subtotal }(95 \% \mathrm{CI})\end{array}$ & 552.42 & $1,231.9$ & $\begin{array}{l}232 \\
232\end{array}$ & $1,077.34$ & $1,231.9$ & $\begin{array}{l}238 \\
238\end{array}$ & $\begin{array}{l}12.0 \% \\
12.0 \%\end{array}$ & $\begin{array}{l}-524.92[-747.68,-302.16] \\
-524.92[-747.68,-302.16]\end{array}$ & & \\
\hline \multicolumn{11}{|c|}{$\begin{array}{l}\text { Heterogeneity: Not applicable } \\
\text { Test for overall effect: } Z=4.62(P<0.00001)\end{array}$} \\
\hline \multicolumn{11}{|c|}{ 1.4.4 Paediatric orthopaedic care } \\
\hline $\begin{array}{l}\text { Ó Mír } 2019 \text { Obs } \\
\text { Subtotal }(95 \% \mathrm{Cl})\end{array}$ & 33.76 & 10.67 & $\begin{array}{l}399 \\
399\end{array}$ & 59.27 & 8.51 & $\begin{array}{l}346 \\
346\end{array}$ & $\begin{array}{l}18.9 \% \\
18.9 \%\end{array}$ & $\begin{array}{l}-25.51[-26.89,-24.13] \\
-25.51[-26.89,-24.13]\end{array}$ & & - \\
\hline \multicolumn{11}{|c|}{$\begin{array}{l}\text { Heterogeneity: Not applicable } \\
\text { Test for overall effect: } Z=36.27(P<0.00001)\end{array}$} \\
\hline Total $(95 \% \mathrm{Cl})$ & & & 2948 & & & 4700 & $100.0 \%$ & $-139.08[-265.93,-12.23]$ & & \\
\hline \multicolumn{9}{|c|}{$\begin{array}{l}\text { Heterogeneity: } \mathrm{Tau}^{2}=22107.77 ; \mathrm{Chi}^{2}=344.37, \mathrm{df}=5(\mathrm{P}<0.00001) ; \mathrm{I}^{2}=99 \% \\
\text { Test for overall effect: } Z=2.15(P=0.03) \\
\text { Test for subgroup differences: } \mathrm{Chi}^{2}=36.23, \mathrm{df}=3(\mathrm{P}<0.00001), \mathrm{I}^{2}=91.7 \%\end{array}$} & $\begin{array}{ll}1 & 1 \\
-500 & -250 \\
\text { Favours } & \text { APP care }\end{array}$ & $e^{1}{ }^{1}$ Favours UMC \\
\hline \multicolumn{11}{|c|}{$\begin{array}{l}\text { Fig. } 2 \text { Funnel plots of health care costs per patient for advanced practice physiotherapy care compared to usual medical care in primary care, } \\
\text { emergency departments and adult and paediatric orthopaedic care. Costs in euro } 2020 \text { (adjusted for inflation \& converted). Health care costs } \\
\text { measured in included studies: salaries, diagnostic tests, medication prescriptions and follow-up care with a } 2 \text { to } 12 \text { months time horizon. Cl: } \\
\text { Confidence intervals; IV: Inverse variance method; Obs: Observational study; RCT: Randomized controlled trial; SD: Standard deviation. McGill, 2017: } \\
\text { Only the between-group differences (APP vs UMC) in health care cost were reported in the original study. O Mír et al., 2019: UMC comparison } \\
\text { group is based on imputed costs }\end{array}$} \\
\hline
\end{tabular}




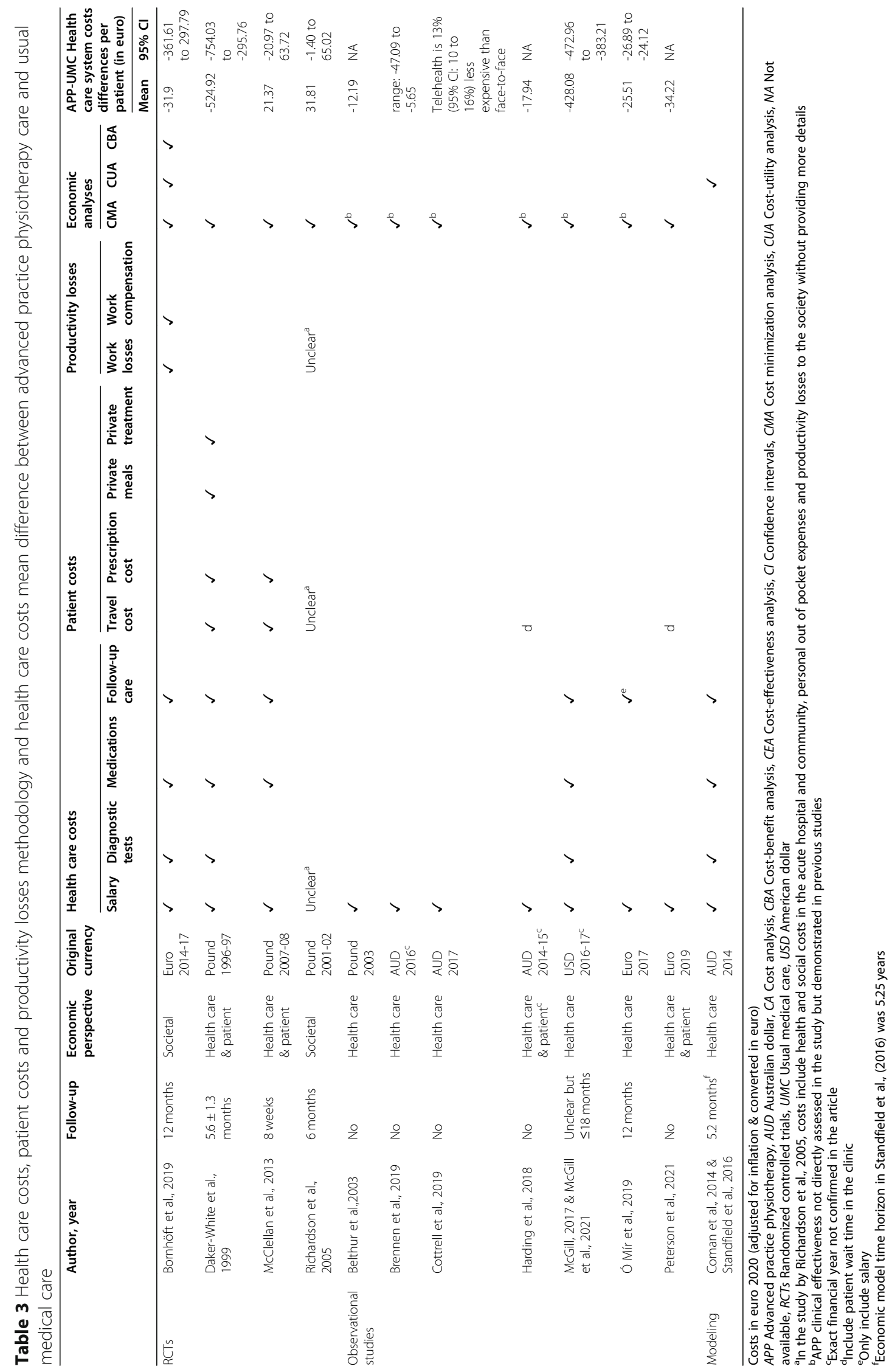




\begin{tabular}{|c|c|c|c|c|c|c|c|c|c|}
\hline \multirow[b]{2}{*}{ Study or Subgroup } & \multicolumn{3}{|c|}{ Favours APP care } & \multicolumn{3}{|c|}{ UMC } & \multicolumn{2}{|r|}{ Mean Difference } & \multirow{2}{*}{$\begin{array}{c}\text { Mean Difference } \\
\text { IV, Random, } 95 \% \mathrm{Cl}\end{array}$} \\
\hline & Mean & SD & Total & Mean & SD & Total & Weight & IV, Random, $95 \% \mathrm{CI}$ & \\
\hline \multicolumn{10}{|l|}{ 3.2.1 Emergency care } \\
\hline McClellan 2013 RCT & 62.95 & 150.72 & 126 & 31.19 & 122.13 & 123 & $71.1 \%$ & $31.76[-2.28,65.80]$ & a \\
\hline Richardson 2005 RCT & 47.96 & 528.52 & 382 & 25.36 & 81.72 & 384 & $28.7 \%$ & $22.60[-31.03,76.23]$ & - \\
\hline Subtotal $(95 \% \mathrm{Cl})$ & & & 508 & & & 507 & $99.8 \%$ & $29.13[0.39,57.87]$ & $\checkmark$ \\
\hline \multicolumn{10}{|c|}{$\begin{array}{l}\text { Heterogeneity: } \mathrm{Tau}^{2}=0.00 ; \mathrm{Chi}^{2}=0.08, \mathrm{df}=1(\mathrm{P}=0.78) ; I^{2}=0 \% \\
\text { Test for overall effect: } Z=1.99(P=0.05)\end{array}$} \\
\hline \multicolumn{10}{|l|}{ 3.2.2 Orthopaedic care } \\
\hline $\begin{array}{l}\text { Daker-W } 1999 \mathrm{RCT} \\
\text { Subtotal }(95 \% \mathrm{Cl})\end{array}$ & 191.85 & $3,572.38$ & $\begin{array}{l}232 \\
232\end{array}$ & 108.36 & $3,572.38$ & $\begin{array}{l}238 \\
238\end{array}$ & $\begin{array}{l}0.2 \% \\
0.2 \%\end{array}$ & $\begin{array}{r}83.49[-562.49,729.47] \\
83.49[-562.49,729.47]\end{array}$ & \\
\hline \multicolumn{10}{|c|}{$\begin{array}{l}\text { Heterogeneity: Not applicable } \\
\text { Test for overall effect: } Z=0.25(P=0.80)\end{array}$} \\
\hline \multirow{2}{*}{\multicolumn{6}{|c|}{$\begin{array}{l}\text { Heterogeneity: } \mathrm{Tau}^{2}=0.00 ; \mathrm{Chi}^{2}=0.11, \mathrm{df}=2(P=0.95) ; \mathrm{I}^{2}=0 \% \\
\text { Test for overall effect: } Z=2.00(P=0.05) \\
\text { Test for subgroup differences: } \mathrm{Chi}^{2}=0.03, \mathrm{df}=1(P=0.87), \mathrm{I}^{2}=0 \%\end{array}$}} & 745 & $100.0 \%$ & $29.24[0.53,57.95]$ & 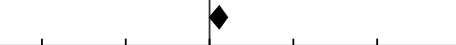 \\
\hline & & & & & & & & & $\begin{array}{llll}-500 & -250 & 0 & 250 \\
\text { Favours APP care } & \text { Favours UMC }\end{array}$ \\
\hline \multicolumn{10}{|c|}{$\begin{array}{l}\text { Fig. } 3 \text { Funnel plots on patient costs per patient for advanced practice physiotherapy care compared to usual medical care in emergency and } \\
\text { orthopaedic care. Costs in euro } 2020 \text { (adjusted for inflation \& converted). Patient costs included: travel costs, waiting time, prescription costs, } \\
\text { private meals, and private treatment with a } 2 \text { to } 6 \text { months time horizon. Cl: Confidence intervals; IV: Inverse variance method; RCT: Randomized } \\
\text { controlled trial; SD: Standard deviation }\end{array}$} \\
\hline
\end{tabular}

the discrete event simulation with dynamic queuing by Standfield et al. [44], the addition of 100 new patients in the multidisciplinary APP MoC would result in an incremental 0.05 QALYs/patient when compared to UMC. The ICER of adding 100 new patients in the multidisciplinary APP MoC is $5518.1 € /$ QALY (95\%CI: 4830.43 to 6241.92).

\section{Economic evaluations of advanced practice physiotherapy} care compared to other health care providers care

Two studies performed cost minimization analyses and compared health system costs with APP care with other health care providers. Two moderate quality studies (one RCT and one cohort study) compared APP care to nurse practitioner care in primary and emergency care were pooled into a meta-analysis [33, 40, 41]. Health care system costs per patient were significantly lower with APP care compared to nurse practitioners care (MD: -136.88 €;
95\%CI: -183.6 to $\left.-90.16 ; n=2613 ; \mathrm{I}^{2}=98 \% ; p<0.0001\right)$ as showed in Fig. 5.

Based on the observational study by McGill [40, 41], health care system costs per patient were significantly lower with APP care compared to osteopathic physicians (MD: $-245.74 €$; 95\%CI: -398.19 to $-93.29 ; n=1926 ; p=$ 0.002 ) or physician assistant care (MD: $-384.37 €$; 95\%CI: -435.27 to $-333.47 ; n=3743 ; p<0.0001)$.

\section{Advanced practice physiotherapy telehealth care compared to face-to-face care}

Based on one low quality observational study in orthopaedic care, telehealth APP care is $13 \%$ (95\% CI: 10 to $16 \%$; $n=44$ ) less expensive than face-to-face APP care with no increase in adverse events reported. The authors concluded that telehealth APP care is a viable option, especially for individuals living in rural areas [42].

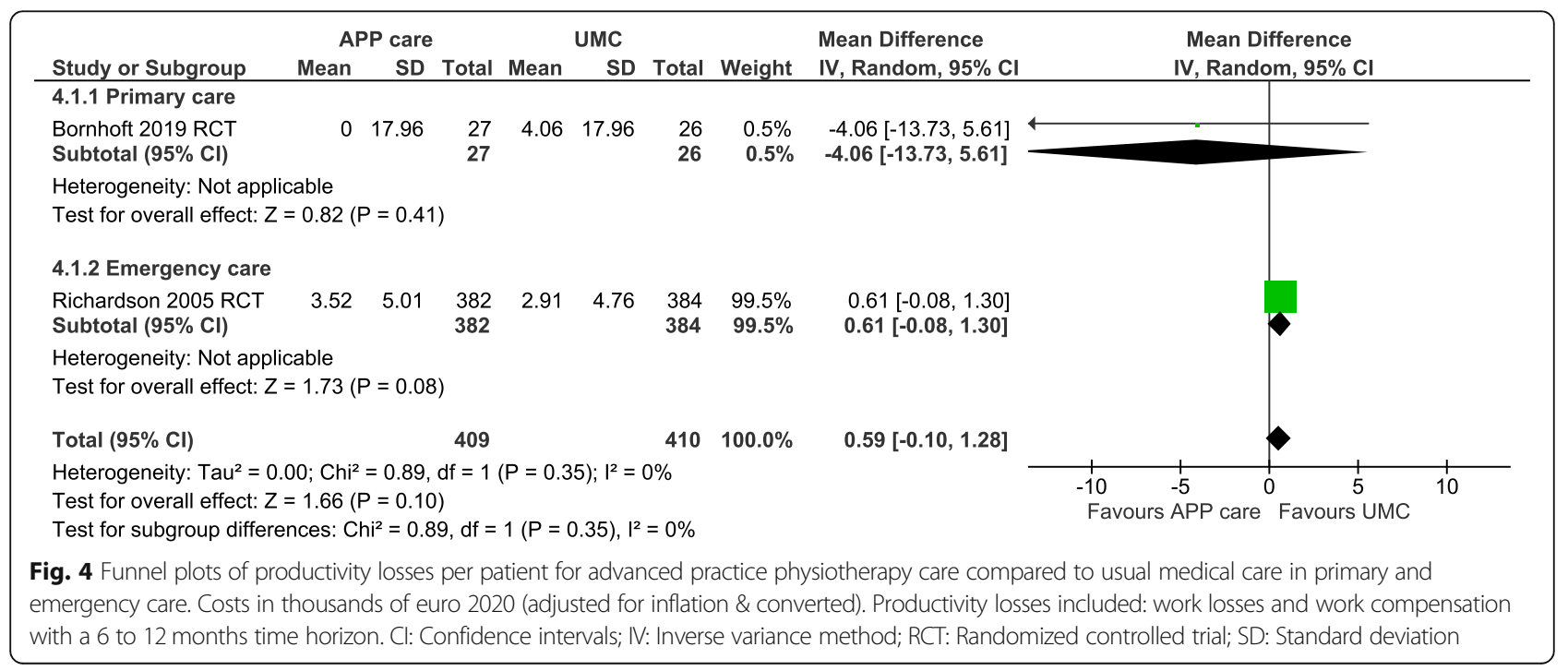




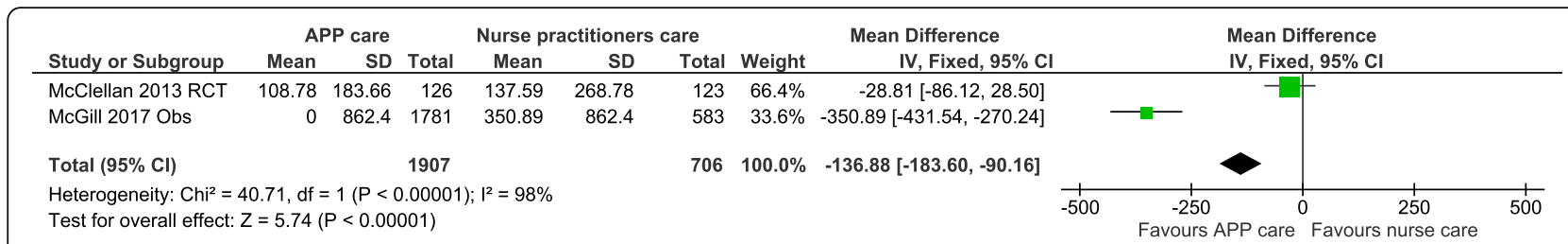

Fig. 5 Funnel plots on health care costs per patient in advanced practice physiotherapy care compared to nurse practitioners in primary and emergency care. Costs in euro 2020 (adjusted for inflation \& converted in euro). Health care costs measured in included studies: salaries, diagnostic tests, medication prescriptions and follow-up care with a $\geq 2$ months time horizon. Cl: Confidence intervals; IV: Inverse variance method; Obs: Observational study; RCT: Randomized controlled trial; SD: Standard deviation. McGill, 2017: Only the between-group differences (APP Vs UMC) in health care cost were reported in the original study. Exact mean costs per patient for APP and UMC were not reported

\section{GRADE approach level of evidence}

Pooled results comparing APP care to UMC were considered of low quality for health system costs and for patient costs and of very low quality for productivity losses results. Pooled result for health care system costs comparing APP care to nurse practitioners care was considered of low quality. See details of Grade Approach and conclusions in Table 4.

Table 4 Summary of findings from meta-analyses and GRADE analyses of the evidence on health care costs, patient costs and productivity losses

\begin{tabular}{|c|c|c|c|c|c|c|}
\hline $\begin{array}{l}\text { Economic } \\
\text { perspective }\end{array}$ & Clinical setting & $\begin{array}{l}\text { Main results }(95 \% \mathrm{Cl}) \\
\text { APP care compared } \\
\text { to UMC }\end{array}$ & $\begin{array}{l}\text { No. of } \\
\text { participants } \\
\text { (RCTs \& } \\
\text { Obs) }\end{array}$ & $\begin{array}{l}\text { Quality of } \\
\text { included } \\
\text { studies based } \\
\text { on EPHPP } \\
\text { (no. of } \\
\text { studies) }\end{array}$ & $\begin{array}{l}\text { Certainty } \\
\text { (GRADE) }\end{array}$ & Conclusions \\
\hline $\begin{array}{l}\text { Health care } \\
\text { costs }\end{array}$ & $\begin{array}{l}\text { Primary, } \\
\text { emergency, } \\
\text { orthopaedic \& } \\
\text { paediatric care }\end{array}$ & $\begin{array}{l}\text { Costs per patient were } \\
\mathbf{1 3 9 . 0 8} € \text { lower }(12.23 \\
\text { to } 265.93) \text { with APP } \\
\text { care }\end{array}$ & $\begin{array}{l}7648 \\
(4 \text { RCTs \& } 2 \\
\text { Obs) }\end{array}$ & $\begin{array}{l}\text { Strong: } 1 \\
\text { Moderate: } 4 \\
\text { Weak: } 1\end{array}$ & $\begin{array}{l}\text { Low } \\
(1,2,4,5)\end{array}$ & $\begin{array}{l}\text { Evidence suggests that health care costs per } \\
\text { patient are lower with APP care than UMC. } \\
\text { Costs difference is large but uncertain, as cost } \\
\text { is higher with APP care in emergency care. }\end{array}$ \\
\hline $\begin{array}{l}\text { Patient } \\
\text { costs }\end{array}$ & $\begin{array}{l}\text { Emergency \& } \\
\text { orthopaedic } \\
\text { care }\end{array}$ & $\begin{array}{l}\text { Costs per patient were } \\
\mathbf{2 9 . 2 4} € \mathbf{~ h i g h e r ~}(0.53 \\
\text { to } 57.95) \text { with APP } \\
\text { care }\end{array}$ & $\begin{array}{l}1485 \\
\text { (3 RCTs) }\end{array}$ & Moderate: 3 & $\begin{array}{l}\text { Low } \\
(2,3)\end{array}$ & $\begin{array}{l}\text { Evidence suggests that patient costs per } \\
\text { patient are significantly higher with APP care } \\
\text { compared to UMC. Costs difference is small. }\end{array}$ \\
\hline $\begin{array}{l}\text { Productivity } \\
\text { losses }\end{array}$ & $\begin{array}{l}\text { Emergency \& } \\
\text { orthopaedic } \\
\text { care }\end{array}$ & $\begin{array}{l}\text { Costs per patient were } \\
590 € \text { higher }(-100 \text { to } \\
1280) \text { with APP care }\end{array}$ & $\begin{array}{l}819 \\
(2 \text { RCTs })\end{array}$ & $\begin{array}{l}\text { Strong: } 1 \\
\text { Moderate: } 1\end{array}$ & $\begin{array}{l}\text { Very low } \\
(2,3,4)\end{array}$ & Evidence is very uncertain \\
\hline \multicolumn{2}{|c|}{ Secondary analysis } & $\begin{array}{l}\text { APP care compared to } \\
\text { nurse practitioners } \\
\text { care }\end{array}$ & & & & \\
\hline $\begin{array}{l}\text { Health care } \\
\text { costs }\end{array}$ & $\begin{array}{l}\text { Primary \& } \\
\text { emergency care }\end{array}$ & $\begin{array}{l}\text { Costs per patient were } \\
\mathbf{1 3 6 . 8 8} € \text { lower }(90.16 \\
\text { to } 183.6) \text { with APP } \\
\text { care }\end{array}$ & $\begin{array}{l}2613 \\
(1 \mathrm{RCT} \& 1 \\
\text { Obs) }\end{array}$ & Moderate: 2 & $\begin{array}{l}\text { Low } \\
(1,2,4,5)\end{array}$ & $\begin{array}{l}\text { Evidence suggests that health care costs per } \\
\text { patient is lower with APP care than nurse } \\
\text { practitioners care }\end{array}$ \\
\hline
\end{tabular}

\section{Results in bold are statistically significant}

1. Initially rated as moderate (some information from observational studies)

2. Downgraded due to risk of bias (most information is from studies at moderate risk of bias)

3. Downgraded due to imprecision of the results

4. Downgraded due to inconsistency of the results

5. Upgraded due to large effect of the results

Health care costs measured in included studies: salaries, diagnostic tests, medication prescriptions and follow-up care with a 2 to 12 months time horizon

Patient costs included: travel costs, waiting time, prescription costs, private meals, and private treatment with a 2 to 6 months time horizon

Productivity losses included: work losses and work compensation with a 6 to 12 months time horizon

GRADE Working Group grades of evidence:

High quality: We are very confident that the true effect lies close to that of the estimate of the effect

Moderate quality: We are moderately confident in the effect estimate: The true effect is likely to be close to the estimate of the effect, but there is a possibility that it is substantially different

Low quality: Our confidence in the effect estimate is limited: The true effect may be substantially different from the estimate of the effect

Very low quality: We have very little confidence in the effect estimate: The true effect is likely to be substantially different from the estimate of effect $€$ euro, APP Advanced practice physiotherapy, Cl Confidence interval, EPHPP Effective Public Health Practice Project, Obs Observational studies, RCT Randomized controlled trial, UMC Usual medical care 


\section{Discussion}

\section{Main findings}

This systematic review synthesizes, for the first time, evidence on the economic evaluations of various APP MoC. Four RCTs, seven analytical cohort studies and one modeling economic study were included. Most of the included participants in these MoC were adults with MSKDs, although infants and children with MSKDs and women with pelvic floor disorders were intended populations in some models. Overall, low quality evidence suggests that APP $\mathrm{MoC}$ lead to lower health care system cost but higher patient cost per patient when compared to UMC.

\section{Strength and limitations}

Strengths of this review include systematic searches of four important bibliographical databases and the use of the validated Effective Public Health Practice Project tool to assess global methodological quality and of the CASP checklist to assess the quality of the included studies and their economic evaluations. The use of GRADE also represents a strength of our review, as it allowed a more objective and standardized analysis of the quality of evidence. Our review also included studies in different clinical setting and countries therefore increasing the generalizability of the results.

However, some limitations need to be highlighted in the interpretation of our results. First, this review is mainly limited by the quality of the available evidence as only one high quality study was included. Although the inclusion of studies from different clinical settings and countries could be seen as a strength, it also led to heterogeneity among the results. Various methodologies were used to estimate health care cost, including slightly different time horizons, which also led to heterogeneity among the results. The presented meta-analyses, and especially the sub-group analyses, are also based on a relatively small number of studies; which could inaccurately estimate the between-study variance, and therefore the precision of the estimates [45]. Many observational studies could not be pooled in meta-analyses as standard deviation from raw results were not available.

\section{Interpretation and implication of the results}

Our meta-analysis suggests that health care system costs per patient are lower with APP MoC than with UMC and the cost saving might be considered large. However, measured costs differences were inconsistent among studies. For example, the sensitivity analysis including only RCTs did not show significant differences in costs between MoC. Furthermore, the subgroup analysis including only the two-emergency care RCTs concluded that APP care is more expensive than UMC, albeit only slightly. This suggests that the costs saving with APP care may be dependent on the clinical setting. However, very large cost saving with APP care were reported in the two other studies that evaluated APP MoC in primary care and in an orthopaedic specialized setting. In the RCT by Daker-White et al. [32], APPs referred 2.4 times fewer patients for surgery while being as effective as the usual $\mathrm{MoC}$ in terms of reduction of patients' pain and disability and resulted in a mean cost saving of $473.04 € /$ patient. In the American observational study by McGill [40, 41], the important cost saving with APP care was largely due to a reduction in physicians' salary and the number of medication prescriptions, leading to a difference in costs of $427.25 € /$ patient. This large difference could be explained by higher medication expenses per capita [46] and medical doctors' salaries [47-49] found in the United States and not found in other studies that are mainly from Europe in this review. Overall, our results suggest that in certain circumstances APP care has the potential to generate very important saving to health care systems when compared to UMC. It is also important to point out that observational studies $(n=4)$ not included in these meta-analyses also systematically reported lower health care costs with APP care (5.65 to $47.09 € /$ patient), although these observational studies only included health care provider salaries as health care costs. In sum, our results do suggest that health care costs per patient are lower with APP care but uncertainties remain and this is likely dependent on several factors such as: in which health care system the MoC is being assessed, reimbursement schemes of physicians and professionals, the MoC clinical setting (as mentioned earlier) and the population being cared for. The exact role of APPs and the types of evaluation and treatments offered are to be considered also as they involve the use of various health care resources such as prescription of imaging tests, medications, injections and referral to rehabilitation or to surgery.

Another finding of our review is that APP care was slightly more expensive from the patient's perspective, but these results should also be interpreted cautiously and have been appraised as being of low-quality evidence in our GRADE appraisal. The cost differences observed are small and they appear to be driven by the two-emergency care RCTs included in our review. In the RCT by Richardson et al. [34], mean patients costs were higher in the APP group, but were highly skewed and influence by extreme values, as mentioned by the authors. In the RCT by Daker-White et al. [32], the mean cost difference was largely attributable to a single patient enrolled in the APP group that opted to pay for a private spine surgery (total cost: 14,397 €).

Results regarding productivity losses should also be interpreted cautiously as they are based on very low quality evidence. The confidence interval of the productivity losses obtained in our review is large and not statistically significant. High uncertainty in the difference in 
productivity losses highlight the need for further research. Several authors report that MSKDs often lead to significant productivity losses among workers [50-52]. Therefore, as APP care may facilitate earlier return to work by decreasing wait time for an initial consultation or by providing better rehabilitation care $[12,19,32,53$, 54], the cost saving could be important, but this as yet to be formally confirmed in future studies on APP.

As discussed above, most of the included studies did not measure costs using a societal perspective limiting our conclusion mainly to the health care system perspective. Also, the methodology to estimate costs varied among the included studies, with some studies only including APP, doctors and administrative staff salaries as health care costs and did not consider other costs such as diagnostic tests or medications.

Our results also suggest that health care system costs are lower with APP care than with other allied health care providers such as nurse practitioners when substituting physicians in new models of care aimed at improving access to care while delivering efficient care. A previous meta-analysis specific to nurse practitioner $\mathrm{MoC}$, reported lower health care cost with nurse practitioner care compared to UMC in primary care [55]. However, the reported cost saving with nurse practitioner care was small (MD: $-6.41 € 2006$; $95 \%$ CI: -9.28 to $-3.55 ; 2$ RCTs, $n=2689$ ). Based on our results and on previous systematic reviews, APP care could be a more cost-effective alternative to usual medical care than care provided by other allied health care providers such as nurse practitioners.

\section{Comparison with previous systematic reviews}

This systematic review is the first to perform a thorough review of all available evidence on the economic evaluation of APP MoC and to perform meta-analyses on health care and patients costs as well as productivity losses compared to UMC. Previous systematic reviews could not conclude on the economic benefits of APP MoC. Indeed, these reviews reported that APP MoC improve health care access while providing at least comparable quality of care than UMC [12-17, 19]. As our results suggest health care system cost saving with APP MoC compared to UMC, the development and implementation of these models is further supported, especially for MSKDs care.

\section{Unanswered questions and future research}

As our results are based on low to very low quality evidence, the true cost differences between APP MoC and UMC might be markedly different from the estimated costs differences, especially for productivity losses, in which our results are very uncertain. The economic evaluation of $\mathrm{MoC}$ is also context dependent and our results might not be generalizable to different countries, especially for non-Western Countries. Therefore, high-quality studies regarding the economic impact of APP MoC in different countries and setting are still needed. These studies should be carefully designed to minimize the potential bias and capture all cost components related to APP MoC. Future studies should also conduct costeffectiveness, cost-utility and/or cost-benefit analyses, as these analyses provide more complete and meaningful data.

\section{Conclusions}

Low quality evidence suggests that health care system costs per patient are lower with APP care than UMC. The overall cost saving may be large but appear inconsistent among studies. Low quality evidence suggests that patient costs were higher with APP care than UMC, although the observed cost difference was small. Regarding productivity losses, the current level of evidence is very uncertain. Costs differences may vary depending on various factors such as the cost methodology used and on the clinical setting. More evidence is needed to fully evaluate cost benefits of APP models of care.

\begin{abstract}
Abbreviations
APP: Advanced practice physiotherapy; APPs: Advanced practice physiotherapists; AUD: Australian dollar; CASP: Critical Appraisal Skills Programme; CBA: Cost-benefit analysis; CEA: Cost-effectiveness analysis; Cl: Confidence intervals; CMA: Cost minimization analysis; CUA: Cost-utility analysis; CT: Computerized tomography; EMG: Electromyography; EPHPP: Effective Public Health Practice Project; GRADE: Grading of Recommendations, Assessment, Development and Evaluations; ICER: Incremental cost-effectiveness ratio; IV: Inverse variance method; MD: Mean differences; MoC: Models of care; MRI: Magnetic resonance imaging; MSK: Musculoskeletal; MSKDs: Musculoskeletal disorders; NA: Not available; Obs: Observational studies; OECD: Organisation for Economic Cooperation and Development; QALYs: Quality-adjusted life years;

RCTs: Randomized controlled trials; SD: Standard deviation; UMC: Usual medical care; USD: American dollar; UK: United Kingdom; X-ray: Radiograph
\end{abstract}

\section{Supplementary Information}

The online version contains supplementary material available at https://doi. org/10.1186/s12913-021-07221-6.

\section{Additional file 1.}

Additional file 2.

Additional file 3 .

\section{Acknowledgements}

We are grateful to Marie Ó Mír for sharing her data in order to make further calculations, to Lena Bornhöft, Paula Harding and Troy McGill to provide further details regarding their models of care and/or results and to Gabriel Barbe to provide us data regarding currency conversions and inflation rates among countries.

\section{Authors' contributions}

SL: Study protocol design, literature searches, study selection, data extraction, risk-of-bias analysis, data analysis and drafting of the manuscript. AD: Review the protocol, study selection, data extraction verification, risk-of-bias analysis, data analysis and reviewing and editing the manuscript. KT: Review the protocol, data analysis and reviewing and editing the manuscript. CS and JF: 
Review the protocol and reviewing and editing the manuscript. FD: Study protocol design, data analysis and supervised manuscript drafting and reviewing. The authors read and approved the final manuscript.

\section{Funding}

The project was funded with Dr. Desmeules' Canadian Institutes of Health Research Program New Investigator Salary and Research Award in Clinical Rehabilitation (201609NCR-375311-130299) and Simon Lafrance, PhD, scholarships (Fondation de l'Hôpital Maisonneuve-Rosemont, REPAR, Réseau Provincial de Recherche en Adaptation-Réadaptation and Fonds LéopoldRenaud from Société inclusive).

\section{Availability of data and materials}

The Excel dataset is available in supplementary materials, for further details, contact the corresponding author (SL).

\section{Declarations}

\section{Ethics approval and consent to participate}

Not applicable.

\section{Consent for publication}

Not applicable.

\section{Competing interests}

Carlo Satanguida declares being the Chief Medical Officer for CareAxis, a non-profit network of care involving advanced practice physiotherapists for adults with spinal pain and being a consultant for Medtronic and for Stryker, two medical devices and technology firms. All the other authors declare no conflict or appearance of conflict of interest.

\section{Author details}

'School of Rehabilitation, Faculty of Medicine, Université de Montréal, Montreal, Quebec, Canada. ${ }^{2}$ Maisonneuve-Rosemont Hospital Research Center, Université de Montréal Affiliated Research Center, Montreal, Quebec, Canada. ${ }^{3}$ INSERM 1123 ECEVE, Faculty of Medicine, Paris-Diderot University, Paris, France. ${ }^{4}$ Physiotherapy School, University of Orleans, Orleans, France. ${ }^{5}$ School of Epidemiology and Public Health, University of Ottawa, Ottawa, ON, Canada. ${ }^{6}$ Ottawa Hospital Research Institute, Ottawa, ON, Canada. ${ }^{7}$ Hôpital du Sacré-Coeur de Montréal Research Center, Université de Montréal Affiliated Research Center, Montreal, Quebec, Canada. ${ }^{8}$ Department of Surgery, Faculty of Medecine, Université de Montréal, Montreal, Quebec, Canada. ${ }^{9}$ Department of Neurology and Neurosurgery, Faculty of Medecine, McGill University Health Center, Montreal, Quebec, Canada.

\section{Received: 9 March 2021 Accepted: 25 October 2021}

\section{Published online: 09 November 2021}

\section{References}

1. OECD: OECD Health Statistics 2019. 2019.

2. Gaskin DJ, Richard P. The economic costs of pain in the United States. J Pain. 2012;13(8):715-24. https://doi.org/10.1016/j.jpain.2012.03.009.

3. Hoy D, March L, Brooks P, Blyth F, Woolf A, Bain C, et al. The global burden of low back pain: estimates from the global burden of disease 2010 study. Ann Rheum Dis. 2014;73(6):968-74. https://doi.org/10.1136/annrheumdis-2 013-204428.

4. Woolf AD, Erwin J, March L. The need to address the burden of musculoskeletal conditions. Best Pract Res Clin Rheumatol. 2012;26(2):183224. https://doi.org/10.1016/j.berh.2012.03.005.

5. Barua B, Moir M. Waiting your turn wait times for health Care in Canada, 2019 report. Canada: Fraser Institute; 2019.

6. Barua B, Moir M. Comparing performance of universal health care countries, 2019. Canada: Fraser Institute; 2019.

7. Contandriopoulos D, Brousselle A, Breton M, Duhoux A, Hudon C, Vadeboncœur $A$, et al. Analyse des impacts de la rémunération des médecins sur leur pratique et la performance du système de santé au Québec. Québec: Fonds de recherche Société et culture Québec; 2018.

8. Speerin R, Needs C, Chua J, Woodhouse LJ, Nordin M, McGlasson R, et al. Implementing models of care for musculoskeletal conditions in health systems to support value-based care. Best Pract Res Clin Rheumatol. 2020; 101548(5):101548. https://doi.org/10.1016/j.berh.2020.101548.
9. Nelson S, Turnbull J, Bainbridge L, Caulfield T, Hudon G, Kendel D, et al. Optimizing scopes of practice: new models of care for a new health care system. Canada: Canadian Academy of Health Sciences Ottawa; 2014.

10. Contandriopoulos D, Perroux M, Cockenpot A, Duhoux A, Jean E. Analytical typology of multiprofessional primary care models. BMC Fam Pract. 2018; 19(1):44. https://doi.org/10.1186/s12875-018-0731-8.

11. Ham C, Dixon A, Brooke B. Transforming the delivery of health and social care. London: Kings Fund Report; 2012.

12. Lafrance S, Lapalme JG, Méquignon M, Santaguida C, Fernandes J, Desmeules F. Advanced practice physiotherapy for adults with spinal pain: a systematic review with meta-analysis. Eur Spine J. 2020;30(4):1-14. https:// doi.org/10.1007/s00586-020-06648-5.

13. Desmeules F, Roy J-S, MacDermid JC, Champagne F, Hinse O, Woodhouse L. Advanced practice physiotherapy in patients with musculoskeletal disorders: a systematic review. BMC Musculoskelet Disord. 2012;13(1):107. https://doi.org/10.1186/1471-2474-13-107.

14. Matifat E, Méquignon M, Cunningham C, Blake C, Fennelly O, Desmeules F. Benefits of musculoskeletal physical therapy in emergency departments: a systematic review. Phys Ther. 2019;99(9):1150-66. https://doi.org/10.1093/ ptj/pzz082.

15. Oakley C, Shacklady C. The clinical effectiveness of the extended-scope physiotherapist role in musculoskeletal triage: a systematic review. Musculoskeletal Care. 2015;13(4):204-21. https://doi.org/10.1002/msc.11 00.

16. Saxon RL, Gray MA, Oprescu FI. Extended roles for allied health professionals: an updated systematic review of the evidence. J Multidiscip Healthc. 2014;7:479-88. https://doi.org/10.2147/JMDH.S66746.

17. Stanhope J, Grimmer-Somers K, Milanese S, Kumar S, Morris J. Extended scope physiotherapy roles for orthopedic outpatients: an update systematic review of the literature. J Multidiscip Healthc. 2012;5:37-45. https://doi.org/1 0.2147/JMDH.S28891.

18. World Confederation for Physical Therapy. WCPT Policy Statement: Advanced Physical Therapy Practice. 2019. https://www.wcpt.org/policy/ps-a dvanced-pt-practice

19. Marks D, Comans T, Bisset L, Scuffham PA. Substitution of doctors with physiotherapists in the management of common musculoskeletal disorders: a systematic review. Physiotherapy. 2017;103(4):341-51. https://doi.org/10.1 016/j.physio.2016.11.006

20. Thomas BH, Ciliska D, Dobbins M, Micucci S. A process for systematically reviewing the literature: providing the research evidence for public health nursing interventions. Worldviews Evid-Based Nurs. 2004;1(3):176-84. https:// doi.org/10.1111/j.1524-475X.2004.04006.x.

21. Armijo-Olivo $S$, Stiles CR, Hagen NA, Biondo PD, Cummings GG. Assessment of study quality for systematic reviews: a comparison of the Cochrane collaboration risk of Bias tool and the effective public health practice project quality assessment tool: methodological research. J Eval Clin Pract. 2012;18(1):12-8. https://doi.org/10.1111/j.1365-2753.2010.01516.x.

22. Critical Appraisal Skills Programme. CASP Economic Evaluation Checklist. 2018. https://casp-uk.net/wp-content/uploads/2018/03/CASP-Economic-Eva luation-Checklist-2018_fillable_form.pdf

23. Bank of England: Database. https://www.bankofengland.co.uk/boeapps/databa se/fromshowcolumns.asp?Travel=NIxIRxSUx\&FromSeries=1\&ToSeries=50\&DAT= $\mathrm{RNG \& FD}=1 \& \mathrm{FM}=J \mathrm{Jan} \& \mathrm{FY}=2020 \& \mathrm{TD}=30 \& \mathrm{TM}=J$ un $\& T Y=2020 \& \mathrm{FNY}=\& C S V F=$ TT\&html. $x=163 \&$ html. $y=28 \& C=5 Y|\& C=5 Y P \& C=60 C \& C=| N 4 \& C=62 R \& F i l t e r=N$.

24. Higgins J, Thomas J, Chandler J, Cumpston M, Li T, Page M, et al. Cochrane handbook for systematic reviews of interventions: Wiley-Blackwell; 2019. https://doi.org/10.1002/9781119536604.

25. Balshem H, Helfand M, Schünemann HJ, Oxman AD, Kunz R, Brozek J, et al. GRADE guidelines: 3. Rating the quality of evidence. J Clin Epidemiol. 2011; 64(4):401-6. https://doi.org/10.1016/j.jclinepi.2010.07.015.

26. Guyatt G, Oxman AD, Akl EA, Kunz R, Vist G, Brozek J, et al. GRADE guidelines: 1. Introduction-GRADE evidence profiles and summary of findings tables. J Clin Epidemiol. 2011;64(4):383-94. https://doi.org/10.1016/j. jclinepi.2010.04.026.

27. Byrnes JM, Comans TA. Medicare rebate for specialist medical practitioners from physiotherapy referrals: analysis of the potential impact on the Australian healthcare system. Aust Health Rev. 2014;39(1):12-7. https://doi. org/10.1071/AH13196.

28. Frogner BK, Harwood K, Andrilla CHA, Schwartz M, Pines JM. Physical therapy as the first point of care to treat low back pain: an instrumental variables approach to estimate impact on opioid prescription, health care 
utilization, and costs. Health Serv Res. 2018;53(6):4629-46. https://doi.org/1 $0.1111 / 1475-6773.12984$

29. Haines T, Kuys SS, Morrison G, Clarke J, Bew P. Cost-effectiveness analysis of screening for risk of in-hospital falls using physiotherapist clinical judgement. Med Care. 2009;47(4):448-56. https://doi.org/10.1097/MLR.0b013 e318190ccc0

30. Van Rossen L, Withrington RH. Improving the standard of care for people with ankylosing spondylitis and a new approach to developing specialist ESP-led AS clinics. Musculoskeletal Care. 2012;10(3):171-7. https://doi.org/1 $0.1002 / \mathrm{msc} .1015$

31. Bornhöft L, Thorn J, Svensson M, Nordeman L, Eggertsen R, Larsson ME. More cost-effective management of patients with musculoskeletal disorders in primary care after direct triaging to physiotherapists for initial assessment compared to initial general practitioner assessment. BMC Musculoskelet Disord. 2019;20(1):186. https://doi.org/10.1186/s12891-019-2553-9.

32. Daker-White G, Carr AJ, Harvey I, Woolhead G, Bannister G, Nelson I, et al. A randomised controlled trial. Shifting boundaries of doctors and physiotherapists in orthopaedic outpatient departments. J Epidemiol Community Health. 1999;53(10):643-50. https://doi.org/10.1136/jech.53.10.643.

33. McClellan CM, Cramp F, Powell J, Benger JR. A randomised trial comparing the cost effectiveness of different emergency department healthcare professionals in soft tissue injury management. BMJ Open. 2013;3(1): e001116. https://doi.org/10.1136/bmjopen-2012-001116.

34. Richardson B, Shepstone L, Poland F, Mugford M, Finlayson B, Clemence N. Randomised controlled trial and cost consequences study comparing initial physiotherapy assessment and management with routine practice for selected patients in an accident and emergency department of an acute hospital. Emerg Med J. 2005;22(2):87-92. https://doi.org/10.1136/emj.2003. 012294

35. Harding P, Burge A, Walter K, Shaw B, Page C, Phan U, et al. Advanced musculoskeletal physiotherapists in post arthroplasty review clinics: a state wide implementation program evaluation. Physiotherapy. 2018;104(1):98106. https://doi.org/10.1016/.jphysio.2017.08.005.

36. Ó Mír M, Rokicki S, Lennon O, OToole PO, Desmeules F, O'Sullivan C. An advanced practice physiotherapy clinic in paediatric orthopaedics: A cost minimisation analysis. Physiother Pract Res. 2019:40(2):155-65.

37. Peterson G, Portström M, Frick J. Extended roles in primary care when physiotherapist-initiated referral to X-ray can save time and reduce costs. Int J Qual Health Care. 2021;33(3):mzab122.

38. Belthur M, Clegg J, Strange A. A physiotherapy specialist clinic in paediatric orthopaedics: is it effective? Postgrad Med J. 2003;79(938):699-702.

39. Brennen R, Sherburn M, Rosamilia A. Development, implementation and evaluation of an advanced practice in continence and women's health physiotherapy model of care. Aust N Z J Obstet Gynaecol. 2019;59(3):450-6. https://doi.org/10.1111/ajo.12974

40. McGill TE. Cost of physical therapists serving as a musculoskeletal providers compared to family practice providers in a military treatment facility; 2017.

41. McGill TE, Stern DF, Kolber MJ, McGee J. Cost outcomes of physical therapist providers compared to primary care providers in the treatment of musculoskeletal patients in a military treatment facility: a retrospective chart review. Int J Allied Health Sci Pract. 2021;19(2):4. https://doi.org/10.46743/1 540-580X/2021.2000

42. Cottrell M, Judd P, Comans T, Easton P, Chang AT. Comparing fly-in fly-out and telehealth models for delivering advanced-practice physiotherapy services in regional Queensland: an audit of outcomes and costs. J Telemed Telecare. 2019:1357633X19858036.

43. Comans T, Raymer M, O'Leary S, Smith D, Scuffham P. Cost-effectiveness of a physiotherapist-led service for orthopaedic outpatients. J Health Serv Res Policy. 2014;19(4):216-23. https://doi.org/10.1177/1355819614533675.

44. Standfield L, Comans T, Raymer M, O'Leary S, Moretto N, Scuffham P. The efficiency of increasing the capacity of physiotherapy screening clinics or traditional medical services to address unmet demand in orthopaedic outpatients: a practical application of discrete event simulation with dynamic queuing. Appl Health econ Health Policy. 2016;14(4):479-91. https://doi.org/10.1007/s40258-016-0246-1.

45. Guolo A, Varin C. Random-effects meta-analysis: the number of studies matters. Stat Methods Med Res. 2017;26(3):1500-18. https://doi.org/10.1177/ 0962280215583568

46. OECD. Pharmaceutical spending: OECD; 2019.
47. Fujisawa R, Lafortune $G$. The remuneration of general practitioners and specialists in 14 OECD countries: what are the factors influencing variations across countries? 2008.

48. OECD. Health care resources : remuneration of health professionals: OECD; 2019.

49. Kane L, Schubsky B, Locke T, Kouimtzi M, Duqueroy V, Gottschling C, et al. International physician compensation report 2019: do US physicians have it best? New York: Medscape; 2019

50. Bevan S. Economic impact of musculoskeletal disorders (MSDs) on work in Europe. Best Pract Res Clin Rheumatol. 2015;29(3):356-73. https://doi.org/1 0.1016/j.berh.2015.08.002

51. Moir M, Barua B. The private cost of public queues for medically necessary care, 2020; 2020

52. Oh I-H, Yoon S-J, Seo H-Y, Kim E-J, Kim YA. The economic burden of musculoskeletal disease in Korea: a cross sectional study. BMC Musculoskelet Disord. 2011;12(1):157. https://doi.org/10.1186/1471-2474-12-157.

53. Desmeules F, Toliopoulos P, Roy J-S, Woodhouse LI, Lacelle M, Leroux M, et al. Validation of an advanced practice physiotherapy model of care in an orthopaedic outpatient clinic. BMC Musculoskelet Disord. 2013;14(1):162. https://doi.org/10.1186/1471-2474-14-162.

54. Bath B, Janzen B. Patient and referring health care provider satisfaction with a physiotherapy spinal triage assessment service. J Multidiscip Healthc. 2012; 5:1-15. https://doi.org/10.2147/JMDH.S26375.

55. Martin-Misener R, Harbman P, Donald F, Reid K, Kilpatrick K, Carter N, et al. Cost-effectiveness of nurse practitioners in primary and specialised ambulatory care: systematic review. BMJ Open. 2015;5(6):e007167. https:// doi.org/10.1136/bmjopen-2014-007167.

\section{Publisher's Note}

Springer Nature remains neutral with regard to jurisdictional claims in published maps and institutional affiliations.
Ready to submit your research? Choose BMC and benefit from:

- fast, convenient online submission

- thorough peer review by experienced researchers in your field

- rapid publication on acceptance

- support for research data, including large and complex data types

- gold Open Access which fosters wider collaboration and increased citations

- maximum visibility for your research: over $100 \mathrm{M}$ website views per year

At BMC, research is always in progress.

Learn more biomedcentral.com/submissions 